\title{
Mycobacterium Leprae: A House Divided?
}

\author{
M. G. CORCOS, M.R.G.S., L.R.G.P., D.T.M. AND H. \\ 'And if a house be divided against itself, that house cannot stand.'*
}

The relationship between the tuberculoid granuloma and the lepromatous infiltrate has always been something of a puzzle. The former appears to be destroying lepra bacilli, whereas the latter seems to be aiding, perhaps even causing their reproduction.

When both these types of response are occurring in the same skin area of a patient, at the same time, what are we to think?

If the foregoing facts are acceptable as a result of the accumulation of evidence gathered over the years, re-examination of ideas about the relationship of the lepra bacillus to human host tissues seems justifiable.

The following two cases are cited, not because they are in any way unusual, but because the findings do seem to point to the extreme probability of tuberculoid and lepromatous responses being functionally opposite in their activity on the bacillus.

CASE I The patient was an Ibo man aged about twenty-seven, who had first noticed signs on his body a few months prior to coming under observation, and had had no treatment of any kind. On examination, his skin showed a few scattered slightly hypopigmented flat macules with rather poorly defined edges. (Fig. I.) In addition to the frank macules, there were faintly hypopigmented areas on the front of the chest, face, arms and legs. With the exception of Macule M., none of the macules showed any anaesthesia, nor central repigmentation. Both ulnar nerves were considerably enlarged, but there was no anaethesia in the peripheral distribution of these nerves when the patient was first seen.

In making skin smears, the slit method of Wade (1935) was employed, the numbers of bacilli seen being indicated by the notation of Dharmendra (1952).

Mitsuda lepromin was used, the early and late results being read. (In this case, the size of the papules was not measured, but the positive readings were only weakly so.) Except where otherwise indicated, all investigations were made before treatment was started. The results are shown in detail in Fig. 2.

The histology at the edge of Macule M., showed tuberculoid and lepromatous features in the same section, both of minor intensity. A few acid-fast bacilli were seen in these sections. The centre of the macule showed resolution, with no acid-fast bacilli, and no recognisable nerve tissue.

*St. Mark, Ch. 3, vs. 25. 


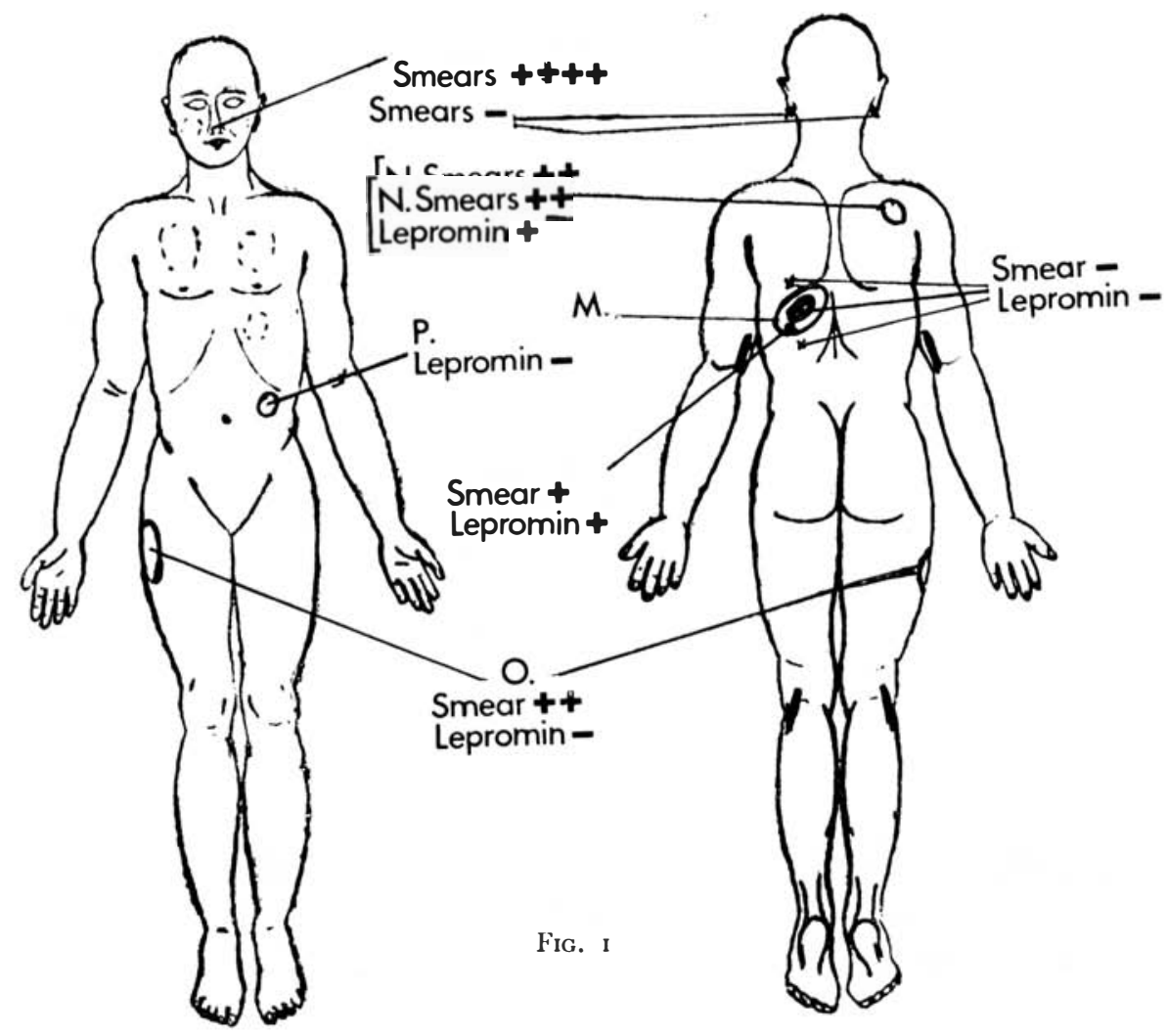

On treatment with Dapsone, the subsequent progress of this patient was excellent. Two years after he had first been seen, all macules had completely disappeared. There was some persistent loss of tactile sensation in the area where macule $M$. had been. There was slight thickening of the right ulnar and right external popliteal nerves, with loss of tactile sensation along the right little finger and the dorsum of the left foot. Otherwise he was fit.

CASE 2 This was a Sierra Leonean man aged about forty-eight. Early in I 949, he had noticed a number of very faint ill-defined patches on his skin for which he was referred for specialist opinion. Skin scrapings and nasal smears were taken, and were repeatedly negative, and at the time, it was evidently not considered that he was suffering from leprosy. A routine medical examination for administrative purposes in $195^{2}$ had shown no obvious clinical abnormality.

He was first seen by me in October 1957 complaining of pain and weakness of both hands and widespread skin lesions, both present since July of that year. On examination, he was found to have extensive raised infiltrated plaques over most of this body. He did not appear to be in lepra reaction, and the temperature was normal. The infiltrated areas showed no loss of pigment (see photograph) and were distributed as in 
S.1. -

L.1. -

S.2.++

B.1.

5.6. -

S.7. +

S.8. - -

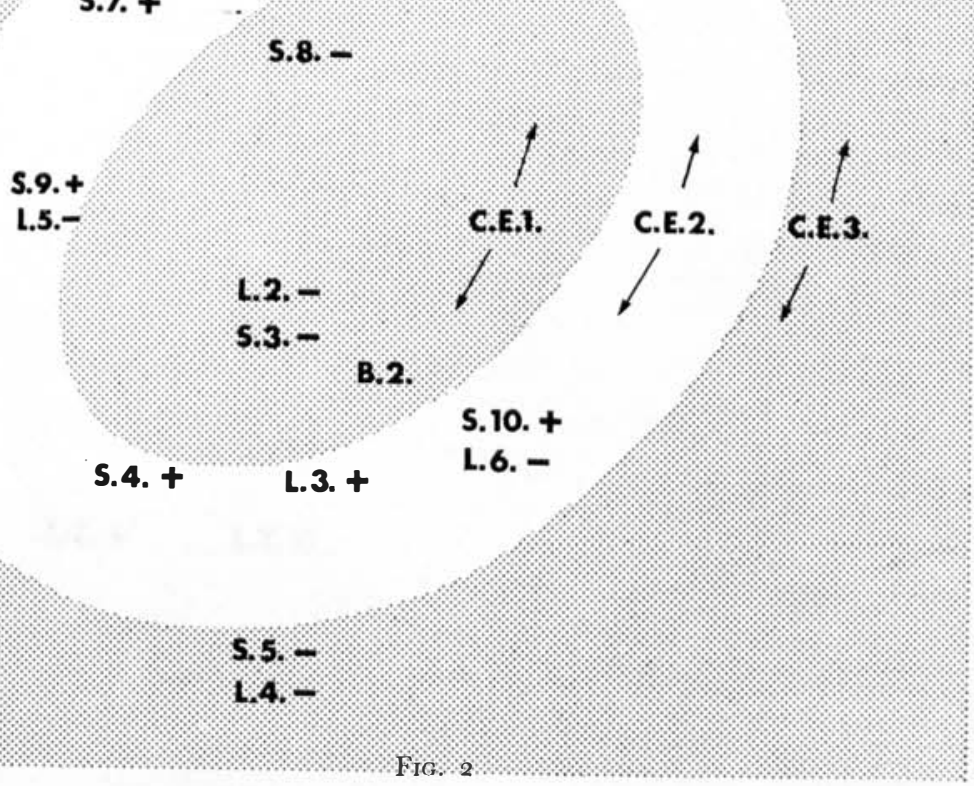

S. I Skin smear for bacilli taken ist May............

S.2 Skin smear for bacilli taken $29^{\text {th }}$ April.............+

S.3 Skin smear for bacilli taken ist May............

S.4 Skin smear for bacilli taken ist May............

S.5 Skin smear for bacilli taken ist May.............

S.6 Skin smear for bacilli taken $\mathrm{I}$ oth May.............

S.7 Skin smear for bacilli taken roth May............

S.8 Skin smear for bacilli taken oth May............

S.9 Skin smear for bacilli taken 29 th May.............

S. 10 Skin smear for bacilli taken 29 th May............

L. I Lepromin injected Ist May............

L.2 Lepromin injected Ist May............

L.3 Lepromin injected Ist May............

L 4 Lepromin injected $\quad$ ist May.............

L.5 I.epromin injected 29 th May...........

L.6 Lepromin injected

(ter starting treatment) 29th May............ (after starting treatment)

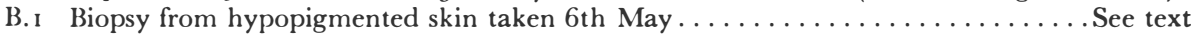

B.2 Biopsy from pigmented skin taken 6 th May.................... See text

C.E. I Clinical examination done on the ist May showed tactile and thermal anaesthesia of the pigmented skin at the centre of the patch.

C E.2 thermal anaesthesia only, of the hypopigmented skin at the periphery.

C.E.3 and no anaesthesia of the normally pigmented skin outside the patch. 
Fig. 3. The patient was able to indicate with some certainty the sites of the original patches. Those over the back of the neck and over the right lower ribs were now concealed by the infiltration, and only an anaesthetic area was present on the back of the right thigh. On the front of the left thigh, however, infiltration was absent over an area of faintly hypopigmented anaesthetic skin, the site of an original patch.

There was marked tactile anaesthesia of both hands and feet, and patchy thermal anaesthesia of some infiltrated areas, especially around the sites of the old patches and on the face. The anaesthesia seemed to bear little relationship to the infiltrated areas, though generally speaking, the markedly infiltrated plaques tended not to be anaesthetic. An area of normal looking skin on which the patient was insistent there had been no previous patch, was anaesthetic to light touch. This area was on the front of the chest just to the right of the midline, in the distribution of the right medial supraclavicular nerve, which was not palpable.

There was bilateral VIIth nerve weakness, weakness of grip of both hands especially the left, and some paralysis of the interossei of both hands with slight wasting, particularly of the first right dorsal interosseous

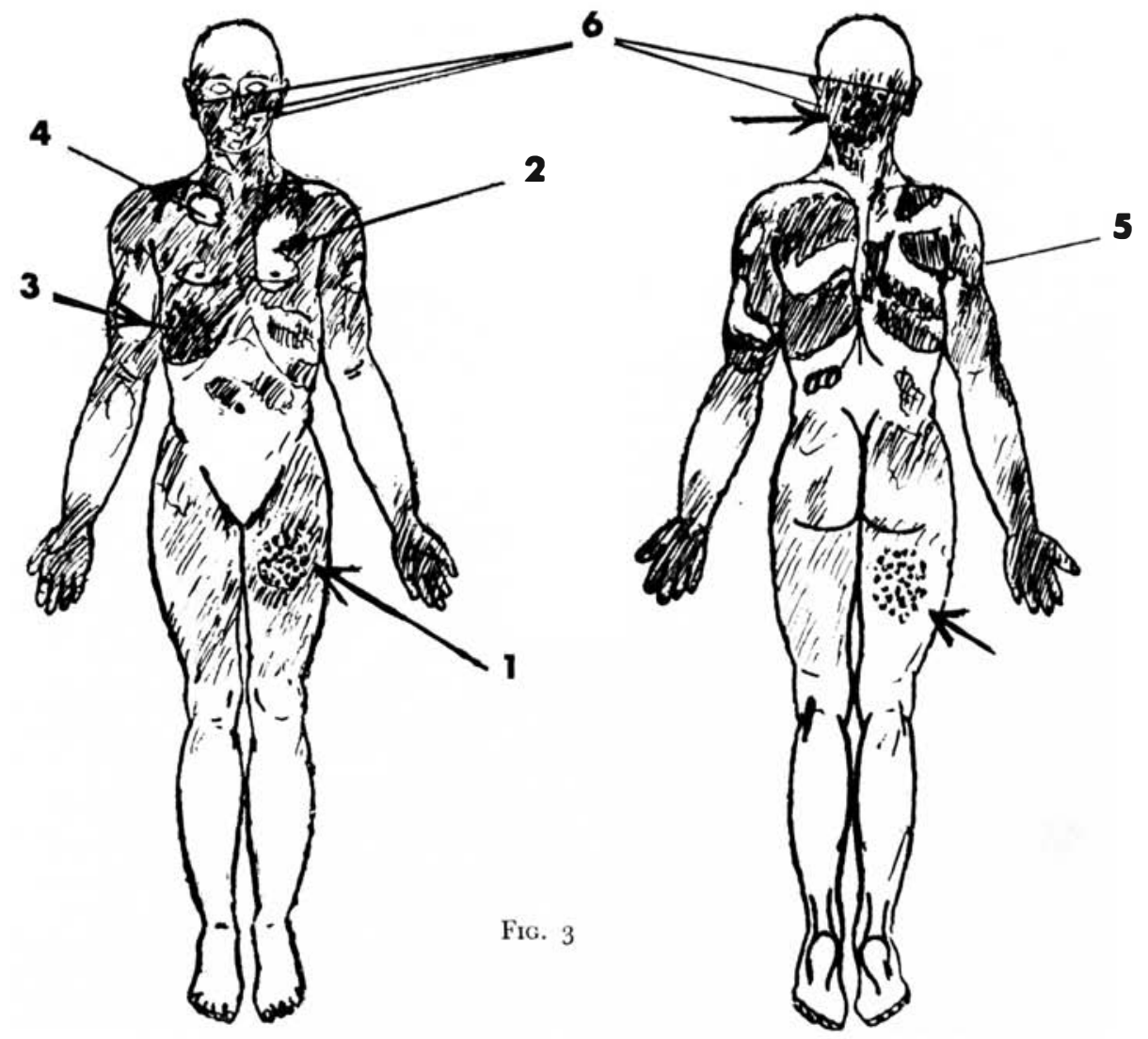

Infiltrated areas shaded, sites of original patches indicated by arrows and stippling.

Numbered sites - see Table I. 
TABLE I

\author{
SKIN SITE (SEE FIG. 3) \\ CLINICAL \\ 4 Oct. I957
}

1. Site of old patch on front of left thigh.

Hypopigmented, anaesthetic, not infiltrated.

2. I.eft chest, believed previously unaffected. Not anaesthetic.

3. Right lower ribs anteriorly. Infiltrated area over site of old patch which is no longer visible. Tactile anaesthesia absent, thermal anaesthesia present.

4. Right upper chest believed previously unaffected. A patch of apparently normal skin, completely surrounded by raised non-anaesthetic infiltration.

5. Right upper arm, believed previously unaffected. Not unaesthetic.

\section{Right ear}

Left ear

Nose ( 8 Dec. I957)

\begin{tabular}{|c|c|c|}
\hline BACTERIOLOGY & \multicolumn{2}{|c|}{ IMMUNOI.OGY } \\
\hline 4()ct. I 957 & Ig Oct & 6 Oct. \\
\hline -ve & $4 \mathrm{~mm}$. & I $\mathrm{mm}$. \\
\hline Normal skin -ve & $4 \mathrm{~mm}$ & -ve \\
\hline I.esion + ve scanty & -ve. & -ve. \\
\hline Normal skin -ve & $2 \mathrm{~mm}$. & I $\mathrm{mm}$ \\
\hline Lesion + ve v. scanty & -ve & $-\mathrm{ve}$ \\
\hline Normal skin —ve & -ve & -ve \\
\hline Lesion + ve scanty & $-v e$ & $-\mathrm{ve}$ \\
\hline Lesion + ve v. scanty & -ve & $-v e$ \\
\hline $\begin{array}{l}\text { +ve } \\
\text { - ve } \\
\text { + ve scanty }\end{array}$ & & \\
\hline
\end{tabular}

2. Edge of infiltrated area, including normal skin.

Dimorphous lesion Lepromatous $>$ Tuberculoid.

3. Edge of infiltrated area including normal skin.

Dimorphous lesion Lepromatous > Tuberculoid.

3. A. April I 958.

Healed.

REMARKS

Despite the rarity of the bacilli in some skin smears, and their extreme rarity in others, those that were found, showed normal staining and morphology. 
muscle. There was rather marked right foot drop present, according to the patient since i954. 'The right external popliteal nerve was palpable but not enlarged. The left external popliteal was very slightly enlarged. Other superficial nerves were clinically normal.

The lack of enlargement of the ulnar nerves was in striking contrast to the intensity of impairment of their function. Areas of thermal anacsthesia surrounded the fully anaesthetic areas on the back of the right thigh and on the front of the left thigh. No anaesthesia was found in the area of distribution of the enlarged supraclavicular nerves.

Investigations carried out before treatment was started, are shown in Table I. Mitsuda lepromin was again used. Where the readings were positive, the diameter of the papule is shown in millimetres. All the carly reactions were negative. The results in the Table are second and third week readings.

On the 29th October 1957, I)apsone therapy was started. 'The lesions underwent clinical change, becoming flatter, more hypopigmented and having slightly more sharply defined edges. On the 25th April i958, a further biopsy was taken from the skin over the right lower ribs close to site $3(=3 \mathrm{~A})$.

On the I 7 th May I958, a further scries of lepromin tests at previously tested sites, was made. The results were as follows:

$$
\text { Ist week } 2 \text { nd week } 3 \text { rd week }
$$

2. Left upper chest. Normal skin. -ve. -ve. -ve.

Left upper chest. Infiltrated skin. -ve. -ve. $2 \mathrm{~mm}$.

3. Right lower ribs. Normal skin. -ve. $3 \mathrm{~mm}$. $3 \mathrm{~mm}$.

Right lower ribs. Infiltrated skin. +ve. $3 \mathrm{~mm}$. $3 \mathrm{~mm}$.

4. Right upper chest. Normal skin. -ve. -ve. -ve.

Right upper chest. Infiltrated skin. -ve. $2 \mathrm{~mm} . \quad-v e$.

5. Right upper arm. Infiltrated skin. -ve. $2 \mathrm{~mm}$. -ve.

Skin smears from the above sites (avoiding the previous lepromin tests) taken on the 7 th June i 958, were all negative.

\section{I S C U S I O N}

A point of interest in these two patients is the relationship of the lepromin results to the lesions. A positive lepromin reaction was found on macule M., in an area clinically similar to one showing lepra bacilli and some degree of lepromatous histology. Other areas of this macule showed negative lepromin reactions despite the fact that the part biopsied was also considered to show tuberculoid histology. Macule N. showing positive skin smears was also lepromin positive at the site tested. Skin sites 2 and 3 in Case 2 were lepromin negative despite the fact that they showed some 
cpithelioid and giant cell histology. Lcpromin negativity of a skin arca already showing epithclioid and giant cells may well be analogous to the failur coflymphocytes in active cases of tubcrculosis to exhibit a mitogenic effect in response to tuberculin, as found by PEARMAIN, LYCETTE and Fitzgerald ( $\left.\mathrm{I}_{96} 63\right)$. It is probably an exhaustion phenomenon, in this case of an initially poor immune responsc.

Positive lepromin reactions in areas showing a tendency to lepra cell infiltration indicate that the ability of an arca to produce a lepromatous response is not directly dependent upon its inability to produce a tuberculoid one. 'This is fur ther borne out by the mixed histology referred to by KHANOLKar (1959) and is exemplified by the sections of sites 2 and 3 in Calsc 2.

If, as scems likely on histological grounds (sCHUJMAN I936, FERNÁNDEz I954), the tuberculoid granuloma is in fact an immune response to bacillary cytoplasm, destroying it, what of the lepromatous response? According to pearmain, Lycette and fitzgerald (ig63), .. 'The ability of immunologically competent cells to respond to antigen by mitosis appears to be a general character of the immune response'. It is therefore worth considering whether the lepromatous response may not also be an immune one directed against another bacillary antigen having quite different properties and behaviour from those of bacillary cytoplasm. Two such cellular responses to two bacillary antigens would accord with the findings of Nossal and Lederberg ( 1958) who showed that when an animal is stimulated with two contrasting antigens, individual cells tend to form one species of antibody.

A tuberculoid response to bacillary cytoplasm involving destruction of the latter, is not hard to envisage, but the lepromatous response is in an altogether different category. A number of workers, including DE SOUZA and DE SOUZA LIMA (I952), and CONVIT, LAPENTA, ILUKEVITCH and IMAEDA (1962), point to the seeming absolute dependence of the lepra bacillus on the lepra cell in order to live and multiply. If therefore the lepra cell is active against a bacillary antigen, this would have to be one tending to cause bacillary reproductive failure, and degradation of bacillary cytoplasm, since bacilli appear to remain morphologically intact and fully capable of reproduction when inside lepra cells (and probably Schwann cells), but fail to reproduce, and degenerate when they become extracellular, or when their host cell regresses.

In contrast to what seems to be the mechanism of the tuberculoid response, we cannot suppose that the lepra cell is destroying an antigen with the above mentioned properties, otherwise we should expect a lepra cell to produce bacilli that were subsequently able to live and multiply extracellularly.

It would be more reasonable to assume that an intra-bacillary factor is being rendered latent and sufficiently innocuous to the bacillus to allow the latter to reproduce. If the resultant bacilli each contained the factor, it would clearly be increasing in amount, in step with bacillary cytoplasm. 
It might well be asked why a lepra cell should behave in the way here suggested. Perhaps it is a question of two antigens sharing the same bacillus but having different target organs. Thus if skin were the target organ of bacillary cytoplasm, whereas nerve tissue were the target organ of a bacillary antigen tending to destroy bacillary cytoplasm and inhibit bacillary reproduction, extreme variation in the pathological picture would result, depending upon the relative sensitivities of the target organs and upon the efficiencies of their immunologically competent protecting cells.

It is unlikely that morphologically intact bacilli are damaging the nerves of lepromatous patients, but quite possible that spontaneously degenerating ones are responsible for this type of damage, both in the later stages of lepromatous leprosy and in tuberculoid lesions.

Thus in Case I, on Macule M, the anaesthesia was maximal at the site of resolution where skin smears were negative, but less at the site of activity where skin smears were positive. ROGERS and MUIR (I946) showed a section of a nerve branch in lepromatous leprosy with clumps of bacilli lying between undamaged nerve fibres. WEDDELL and PALMER ( 1963 ) have drawn attention to the findings of a fasciculus in a nerve bundle of a patient showing a tuberculoid lesion, undergoing degenerative changes in association with acid-fast 'dust', whereas an intact portion of the nerve bundle of the same patient showed two viable organisms lying in healthy Schwann cells related to healthy nerve fibres.

Supposing for the sake of argument, we term bacillary cytoplasm 'bacillary antigen', and the antigen against which lepra and possibly Schwann cells are assumed to be active 'anti-neural antigen', then the kind of dynamic relationships to be expected are shown diagrammatically in Fig. 4 .

The behaviour of 'anti-neural antigen' as here envisaged, is suggestive of the presence in each bacillus of a biological self-replicating particle, possibly of a phage or virus-like nature. It is known that phages as well as having the lytic properties easily seen under laboratory conditions, may exhibit latency, and may also alter properties such as virulence and flagella production in their bacterial hosts (sTOKeR I957). As long ago as I939, CRUIKSHANK put forward the idea of the breakdown of a bacillus-phage complex having pathogenic effects in man, and it is known that the DNA of some phages is antigenic (BURNET I 963). In nature of course, it may be extremely difficult to distinguish between effects brought about by a phage, and those caused by a bacterial gene.

It will be appreciated that in a concept of the kind under discussion, the macrophage that will later become a lepra cell, must be something more than a scavenger. If it is to be regarded as inhibiting a neuropathogenic factor in a lepra bacillus which reproduces as a consequence, some degree of negative neurotropism would be expected of it. It may be that the 'ideal' lepra cell after engulfing a degenerating bacillus threatening a nerve fibril, moves away from the nerve to a safe distance before 


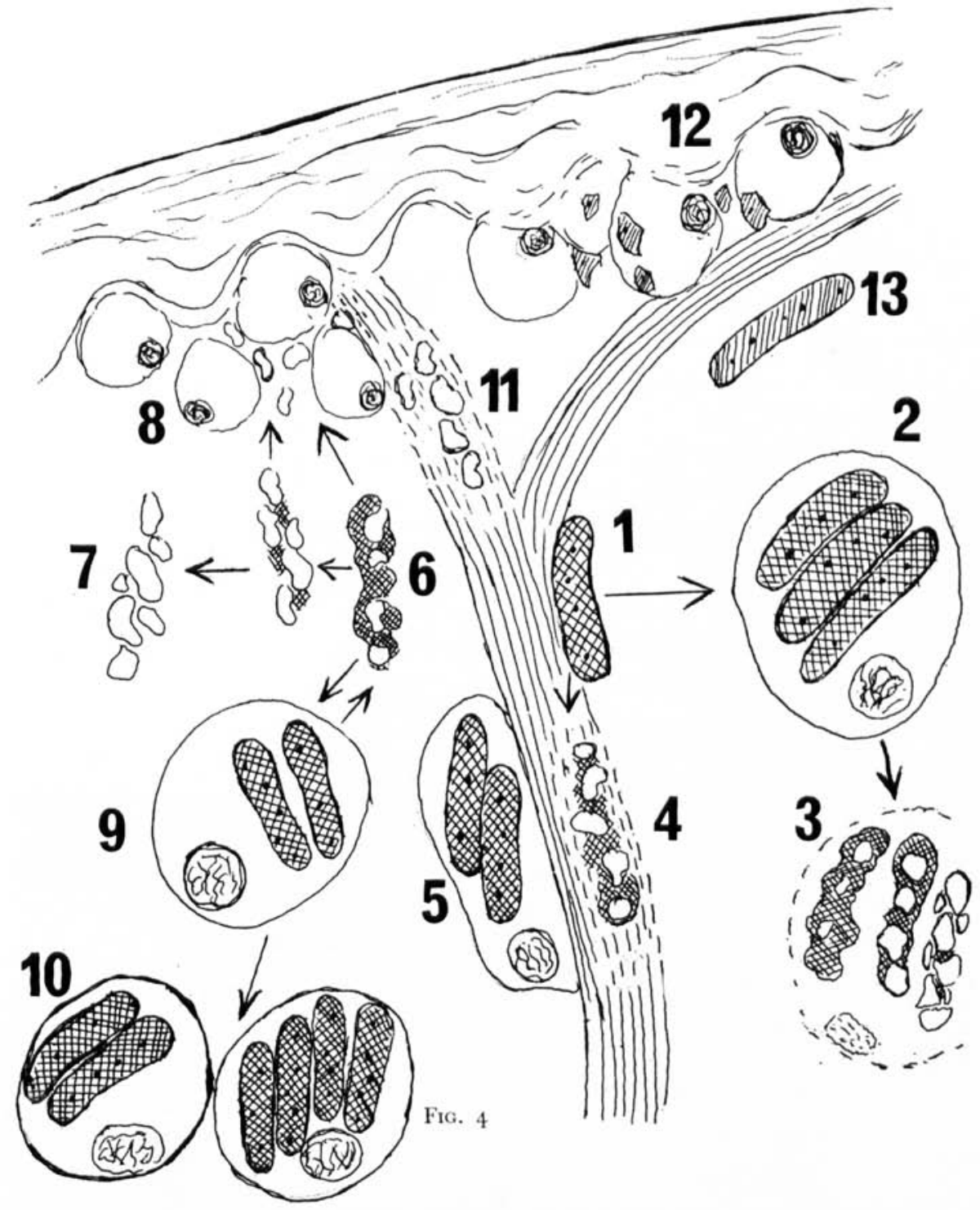

LEGEND TO FIGURE 4

= Live 'bacillary antigen' (= bacillary cytoplasm). Harms skin.

.. = Latent 'anti-neural antigen', alive or dead. Harmless to nerve.

$\varsigma_{00}$ = Active 'anti-neural antigen'. Harms nerve.

IIIIII = Killed 'bacillary antigen' (= lepromin).

The arrows indicate stages in pathogenesis, not movement.

1. Live extracellular bacillus adjacent to nerve. 'Anti-neural antigen' still latent. No nerve damage. 
2. Bacillus engulfed by lepra cell. 'Anti-ncural antigen' kept in latent state, therefore bacillus reproduces and 'anti-neural antigen' increases.

3. Lepra cell degencrates, therefore 'anti-neural antigen' becomes active, and in each bacillus increases at expense of 'bacillary antigen'.

4. Antigens behaving as in $\mathbf{3}$ above, but in nerve fibre which is damaged by 'anti-neural antigen'.

5. Schwann cell behaving like lepra cell, protecting nerve by keeping 'anti-neural antigen' latent, and therefore bacilli morphologically intact.

6. Live 'anti-neural antigen' destroying live 'bacillary antigen' when both are at a distance from nerve.

7. The process completed, no 'bacillary antigen' remains, and there is no tissue damage.

8. Lepra cells protect bacilli from epithelioid cells, which can only affect extracellular forms. 'The decreasing 'bacillary antigen' is destroyed, but the increasing 'anti-neural antigen' is ignored by epithelioid cells and remains free to inflict nerve damage.

9. Degenerating lepra bacillus is engulfed by lepra cell, 'anti-neural antigen' is rendered latent, bacillus regenerates and reproduces in cell.

10. When functional efficiency of lepra cell begins to decline, increased amounts of latent 'anti-neural antigen' begin to become active (sec $\mathbf{3}$ ). This activity is mitogenic to the lepra cell, which divides. The two daughter cells again become efficient in maintaining 'anti-ncural antigen' in the latent state, and bacillary reproduction is maintained.

I1. Nerve in tuberculoid part of lesion damaged by 'anti-neural antigen'. 12. Positive lepromin reaction. Heat stable whole killed bacilli broken down and destroyed by epithelioid cells.

13. Negative lepromin reaction. Killed 'bacillary antigen' tolerated by tissues of lepromatous patient or area. 'Anti-neural antigen' killed while in latent state has lost potential antigenicity and pathogenicity.

shedding the resultant increased bacillary load into the connective tissue and reverting to its undifferentiated state.

The bacilli degenerate harmlessly, and the human host does not get leprosy. Trouble might well start where a lepra bacillus is taken up by a relatively non-motile cell having a high potentially for (indirectly) inducing bacillary reproduction, and for division in order to 'keep pace' with its increasing bacillary load.

It is felt that the clinico-pathological picture in the two cases here presented is explicable on the basis of skin and nerve sensitivities to two bacillary antigens related to each other in the manner described. Other forms of leprosy and of freedom from it may be similarly explained. Thus pure lepromatous leprosy results from the infection of a person whose nerves are sensitive to 'anti-neural antigen' but whose skin is tolerant of 
'bacillary antigen'. 'I'uberculoid and mixed lesions are produced where nerves are sensitive to 'anti-neural antigen' and skin is sensitive to bacillary antigen, the precise clinical type depending upon the relative magnitudes of the two sensitivities and upon the efficiencies of the two kinds of immunologically competent protecting cells in relation to them. A person whose skin is sensitive to 'bacillary antigen' but whose nerves are tolerant of 'anti-ncural' antigen would be lepromin positive but incapable of acquiring leprosy, since there would be no stimulus to the production of lepra cells in his tissues, hence no bacillary multiplication. Similarly, a person whose skin is tolerant of 'bacillary antigen' and whose nerves are also tolerant of 'anti-neural antigen', would be lepromin negative, but equally incapable of acquiring leprosy. 'The same considerations could well apply to skin areas rather than persons.

'Anti-ncural antigen', if it exists might well be difficult to demonstrate, especially if it is heat labile. It may be thought of in its active form as occupying the same space as bacillary cytoplasm but as having an inverse time relationship with it, and the temptation is strong to identify it with the non-stainable electron transparent material that seems to displace cytoplasm in extraccllular forms. It could be that in looking at a 'granular form' we are witnessing not so much the death of a bacillus as a stage in the transformation of a lowly form of life into a yet lower one. The concept of the spontaneous change of one living antigen into another only prevented by the increase of both may give a clue to the mechanisms involved in lepra reaction, but this paper is too short to explore these further possibilities.
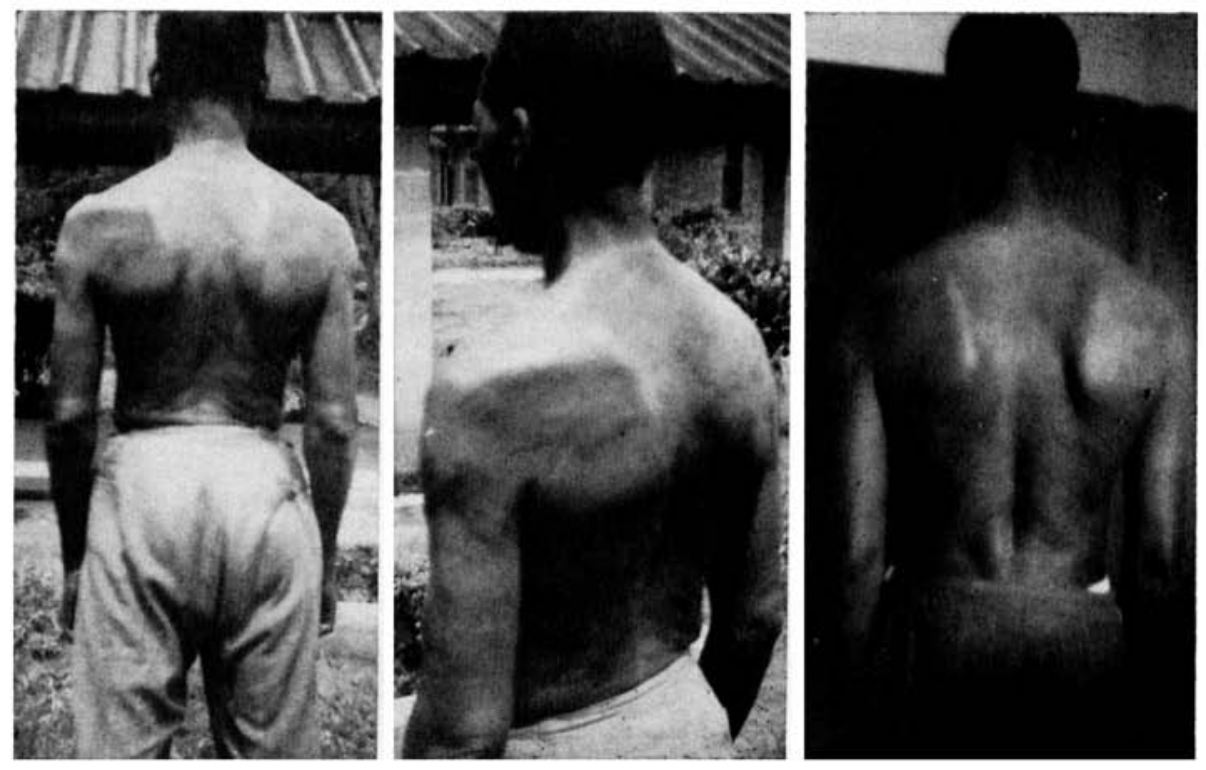

Ciase 2. When first seen.

CAse 2. Seven months after the start of treatment. 
REPORT ON BIOPSY SPECIMENS FROM CASE 2

(See Table I)

SITE NO. I

H. E. Section 'There is a round cell and histiocytic infiltration underneath the epidermis of slight intensity with some evidences of a narrow but free subepidermal zone. In the corium proper there seems to be a considerable increase in collagen, and very few recognisable skin appendages. There is one area where there is a small focus of epithelioid cells. In one or two areas of slight infiltration there appears to be nerve tissue. This is rather difficult to be certain of, otherwise, there is nothing very characteristic about this section, and one would consider that there is considerable evidence of fibrosis or scarring.

F. F. Stain No acid fast bacilli seen.

Diagnosis 'This is consistent with a lesion which is healed. It is not possible to type or group the case. 'The only indication is the residual focus of epithelioid cells, but this is not characteristic enough to give an opinion on the section.

SITE NO. 2

H. E. Section There is a broad band of infiltration below the epidermis leaving a clear subepidermal zone. The infiltrate consists of round cells and histiocytes some of which have the appearance of epithelioid cells and there is an occasional giant cell. It is difficult to say whether there is any foamy cell change or not. 'This is a section fixed by the Ridley's technique, and there may have been a little distortion of the cellular elements. In the dermis proper a similar infiltrate is seen around the appendages of the skin and there are one or two quite definite epithelioid foci with again, an occasional giant cell. One nerve shows interesting infiltration, the epineurium is proliferated, and there are epithelioid cells in the centre of the nerve.

F. F. Stain No acid fast bacilli seen. The nerves in this section are more easily recognised and there seems to be some increase in Schwann cells.

Diagnosis This is a dimorphous lesion considerably nearer to the lepromatous end of the spectrum rather than the tuberculoid, but the fact that there are no acid fast bacilli seen in Fite section makes it difficult to say more than this.

SITE NO. 3

H. E. Section Again there is a broad band of granulomatous infiltration underneath the epidermis leaving a clear subepidermal zone. The infiltrating cells consist of macrophages, round cells and some of the macrophages are definitely epithelioid cells, there appears also to be some foamy cell change. In the deeper parts of the dermis there is the appearance of increased collagen, round the appendages of the skin there is a similar infiltrate. Here there are one or two giant cells and one or two definite epithelioid foci. Nerves by and large are uninvaded although there is an increase in the cellular $\mathrm{e}^{\mathrm{l} e m e n t}$ and a proliferation of the epineurium.

F. F. Stain Again, unfortunately, no acid fast bacilli are seen.

Diagnosis This appears to be a dimorphous lesion, nearer to the lepromatous end of the spectrum than the tuberculoid. The absence of acid fast bacilli suggests that there is still a considerable tuberculoid element in the section.

SITE NO. 3A

Taken on 25 April 1958 from close to site No. 3. At this time the patient was undergoing oral Dapsone treatment.

H. E. Section Scattered round-celled and histiocytic infiltration immediately underneath the epidermis of moderate intensity. In the deeper layers of the corium there is considerable increase of collagen fibres and there is very little evidence of skin appendages. There is also a slight round-celled infiltration. No nerves definitely seen.

F. F. Stain No acid-fast bacilli.

Diagnosis This is an indeterminate or undiagnostic histology, but would fit in with a healed or scarred lesion. 


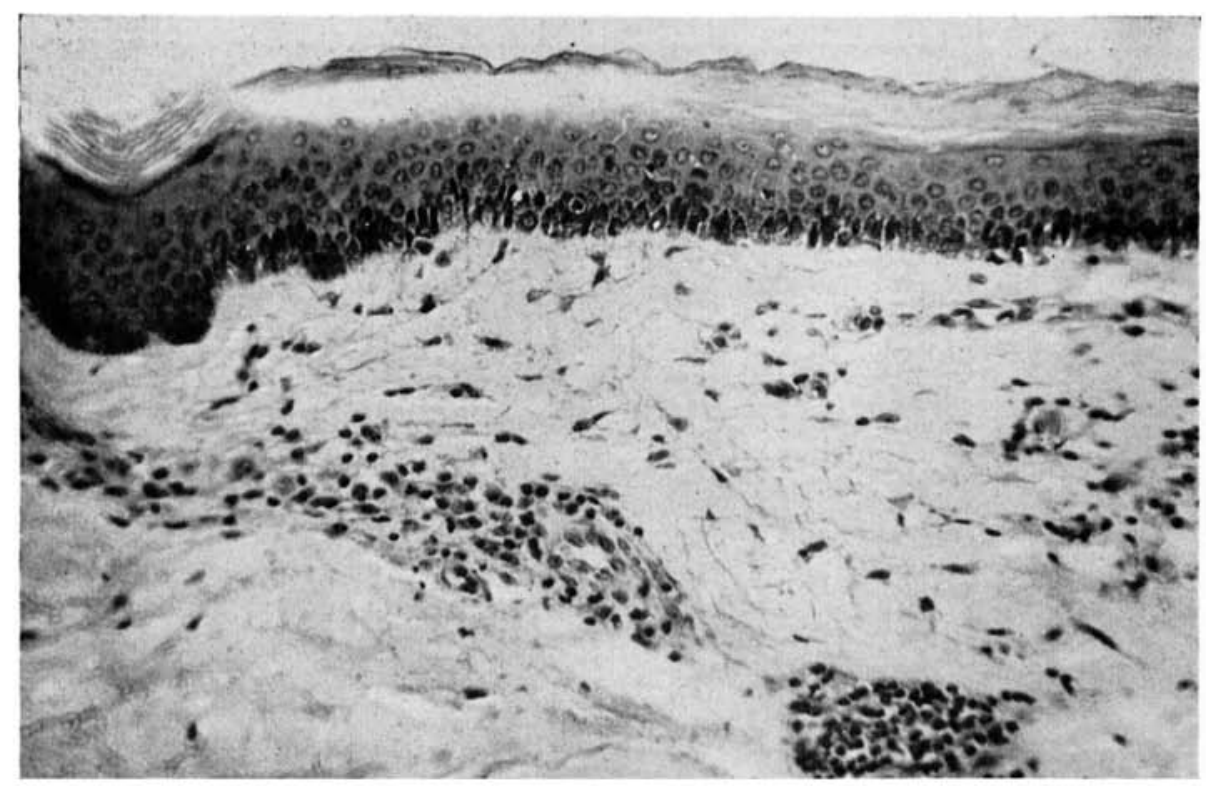

CiAse 2. Section from site No. I. Fite-Faraco stain. $\times 300$.

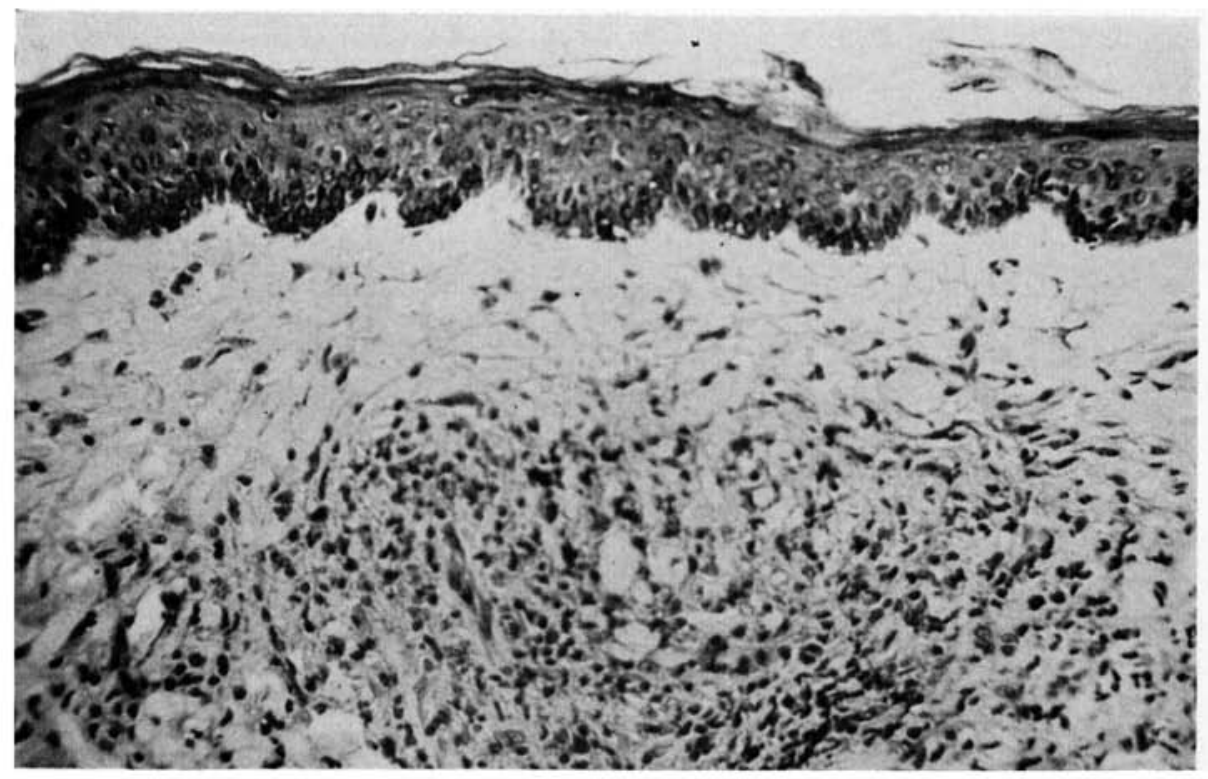

Case 2. Section from site No. 2. Fite-Faraco stain. $\times 300$. 


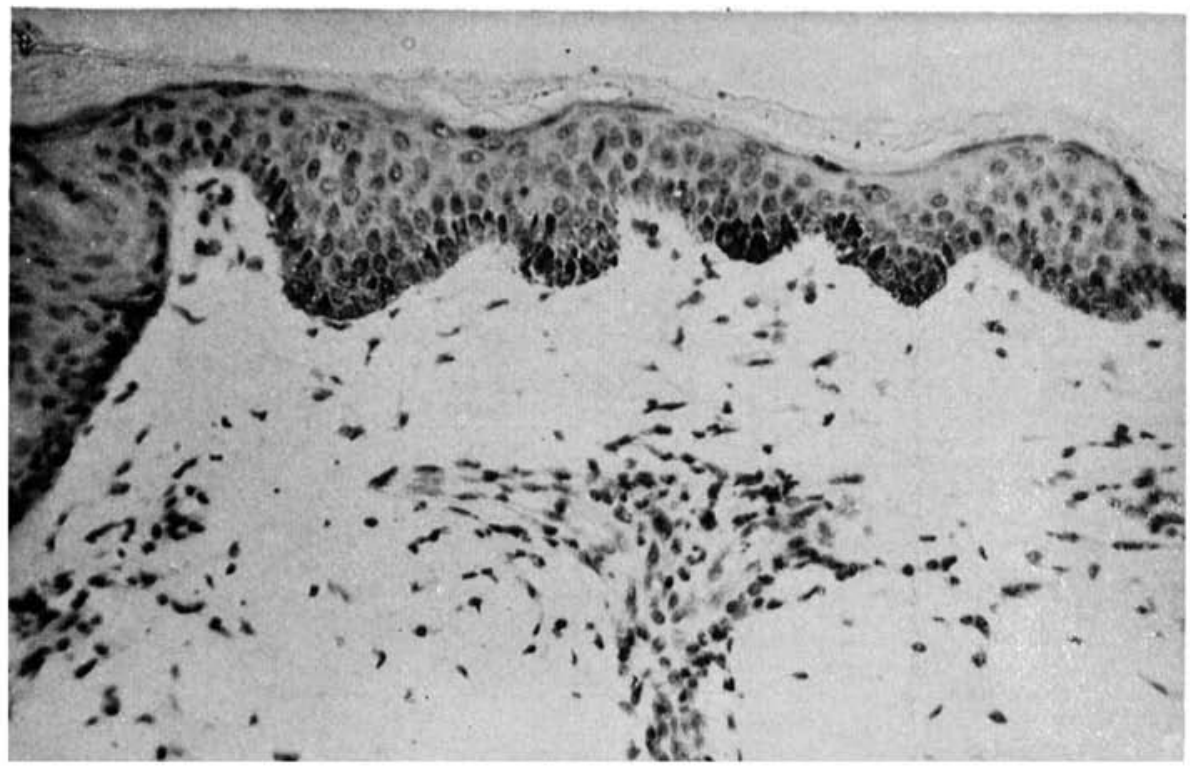

CASE 2. Section from site No. 2. Haematoxylin and eosin stain. $\times 300$.

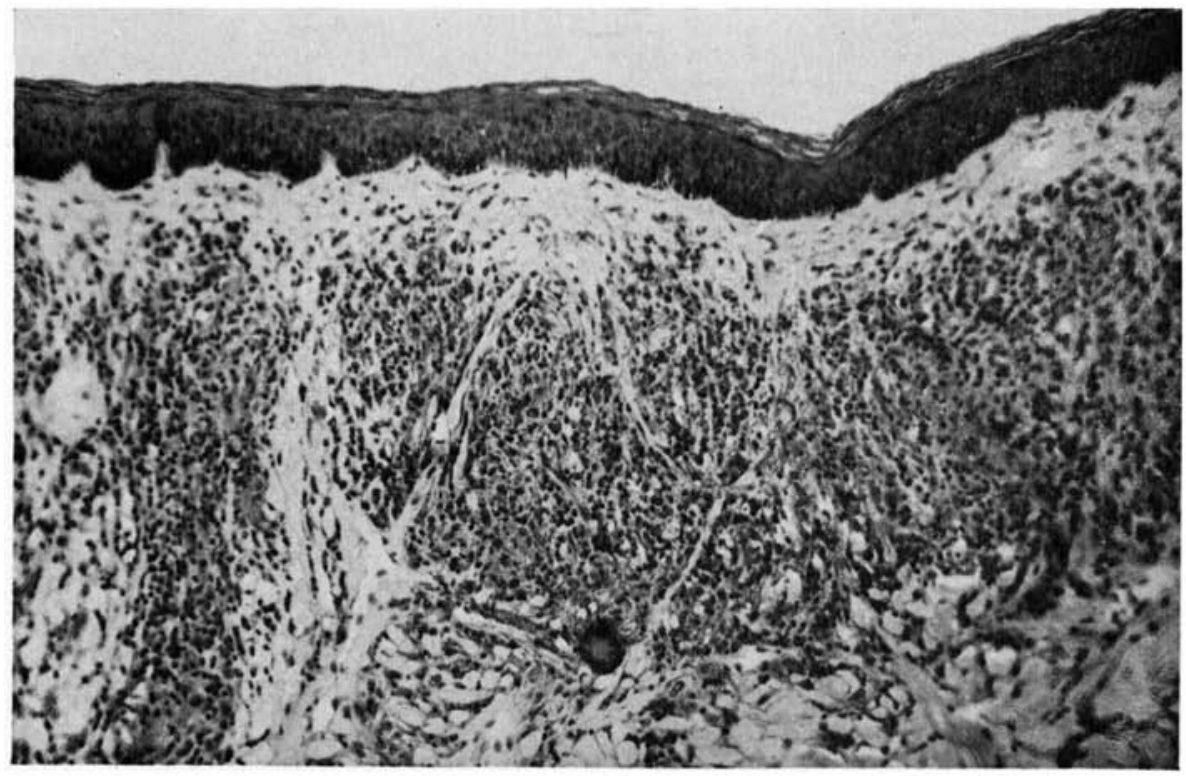

CASE 2. Section from site No. 3. Fite-Faraco stain. $\times$ I 50 . 


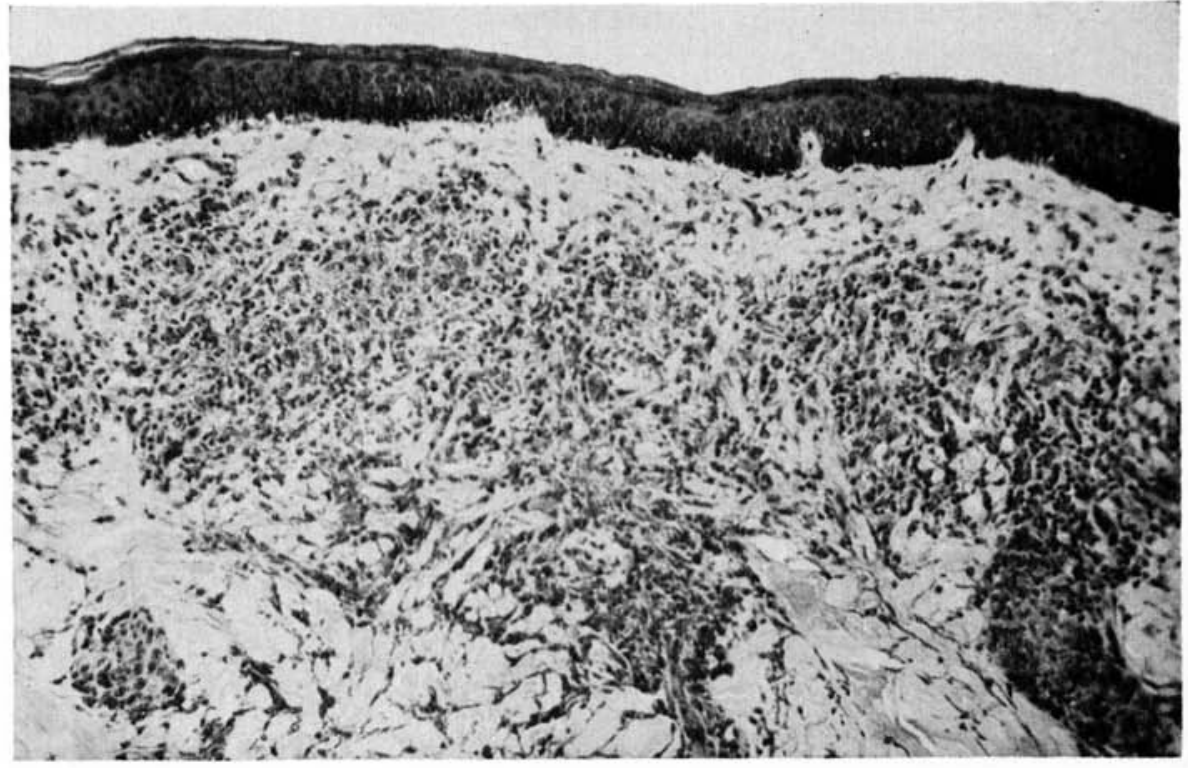

CAse 2. Section from site No. 3. Fite-Faraco stain. $\times$ I 50 .

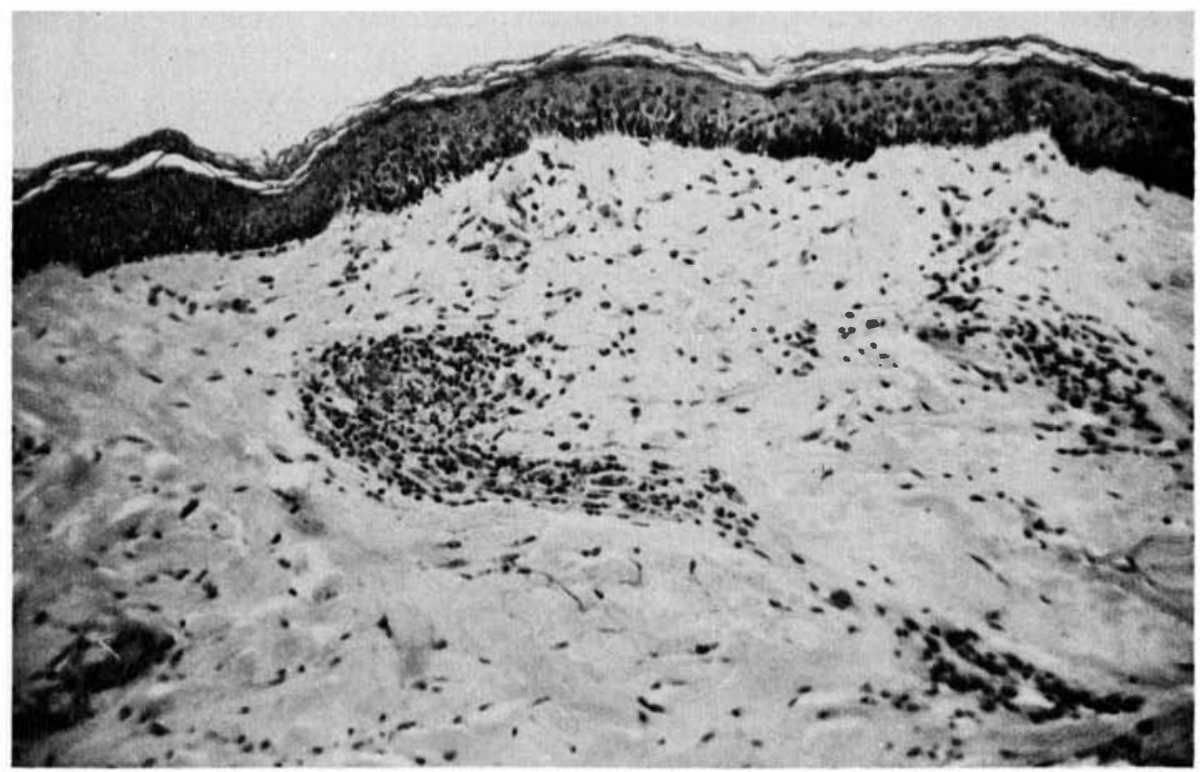

Case 2. Section from site No. 3A. Fite-Faraco stain. $\times 150$. 


\section{S U M M A R Y}

Two cases of leprosy of mixed type are described. Bacilli were not found in the clinically normal skin of either case, whether it was lepromin positive or negative, but they were present in the lesions which showed features of the tuberculoid and lepromatous responses intermingled with each other.

The presence of a poorly developed lepromatous infiltrate did not appear to exclude a positive lepromin reaction in a clinically similar part of the lesion neither did the prior development of epithelioid and giant cells exclude lepromin negativity of the lesion very close to where they were found.

On the basis of these findings, the following is suggested:

There are two antigens in each leprosy bacillus. The one to which the tuberculoid granuloma is the response is bacillary cytoplasm. It is heat stable and has the skin of sensitive subjects as its main target organ. It is destroyed by epithelioid and giant cells, and also by another heat labile bacillary antigen which when active also causes damage to nerve in sensitive subjects. This second antigen is rendered latent by lepra and Schwann cells, and hence harmless both to nerves and bacilli. The latter are thereby enabled to reproduce. The second antigen may be a living self-replicating particle always carried by lepra bacilli.

\section{A CKNOWLEDGEMENT}

I am indebted to DR. T. F. DAVEY, DR. R. G. COCHRANE, DR. G. BERRY, MR. J. UWOM, MR. D. WHITE, MISS F. MCNULTEY and MISS A. BOYNES for their help in the collection and preparation of the material on which this paper is based. None of these workers necessarily endorses the views expressed in the discussion, for which I must bear the sole blame.

I would particularly like to thank the two patients for their willing and intelligent co-operation.

\section{References}

BURnet, M. Experimental Production of Auto-Antibodies or of Auto-Immune Disease. British Medical Bulletin. (1963), 19, 3. p. 247.

Convit, J., LApenta, P., ilukevitch, A. and imaeda, T. Experimental Inoculation of Human Leprosy in Laboratory Animals. 1. Int. J. Leprosy, (1962) 30, 3, p. 243-246.

Cruikshank, D. B. Papworth Research Bulletin, (1939), Pendragon Press, Papworth, 2.

Dharmendra. Cited by Cochrane, R.G. Bacteriological Index in Leprosy, Leprosy Rev. (1952) 23, 3 and 4 , p. 136 .

FERNÁNDEZ, J. M. M. Bacteriologia de la lepra. Investigaciones para dilucidar si el Mycobacterium leprae esta muerto o vivo. Valor del metodo de Ziehl Neelsen. Med Panamericana (1954), 3, abstr. in Int. J. Leprosy, (1962) 30, 4, p. 504.

Khanolkar, v. R. Pathology of Leprosy, in Leprosy in Theory and Practice, (1959), Cochrane, R. J., Bristol: J. W'right \& Sons, Ltd., p. 88.

NOsSAL, G. J. v. and Lederberg, J. Nature, London, (1958), 181, 1419. quoted in The Lancet, (1958), 1, pp. 1321-1322. 
Rogers, I. and muir, E. Leprosy, (1946), Bristol: J. Wright \& Sons, Ltd., Fig. 79.

schujman, s. Histopatologica de la reaccion de Mitsuda: Fstudio progressivo y comparativo de las reacciones tisulares que provoca en las diversas formes clinicas de la lepra. Rev. Brasiliera Leprol, (1936), 4, pp. 469-476. abstr. in Int. J. Leprosy, (1962), 30, 4, p. 505.

souza, p. R. de, and souza lima, m. de, The Mechanism of Action of the Sulfone Derivatives in Lepromatous Leprosy. Int. J. Leprosy, (1952), 20, 3, pp. 365-376.

STOKer, M. G. P. Latent Infections with viruses and Rickettsiae. Br. Med. Journ. 27 Apr. 1957, pp. $963-968$.

WAdE, H. W. The Bacteriological Examination in Leprosy. Leprosy Rev. (1 935), 6, 3, p. 54.

weidele, G. and Paimer, E. 'The Pathogenesis of Leprosy, Leprosy Rev. (1963), 34, 2, pp. 58-59. 